\title{
Controle de contaminação e oxidação no cultivo in vitro de oliveira (Olea europaea L.) cv. "Koroneiki"
}

Control of contamination and oxidation in the in vitro cultivation of olive tree (Olea Europaea $\mathrm{L}_{\text {. }}$ ) cv. "Koroneiki "

Control de la contaminación y oxidación en el cultivo in vitro de oliveira (Olea europaea L.) cv. "Koroneiki"

\section{Resumo}

A micropropagação da oliveira é um método utilizado para se obter várias mudas sadias em menor tempo, comparada às técnicas tradicionais, a partir de um explante. Dessa forma, o objetivo deste trabalho foi definir um protocolo de controle de contaminação e oxidação de explantes de Oliveira (Olea europaea L.) cv Koroneiki. Assim foram realizados dois experimentos em delineamento inteiramente casualizado. O primeiro experimento foi conduzido em esquema fatorial $2 \mathrm{X} 4$, utilizando-se de duas formas de desinfestação dos explantes com hipoclorito de sódio ( $\mathrm{NaClO})$ $(1,5 \% \mathrm{NaClO} / 15 \mathrm{~min}$ e $2,5 \% \mathrm{NaClO} / 5 \mathrm{~min})$ e quatro concentrações de cravo-da-índia (Caryophyllus aromaticus L.)

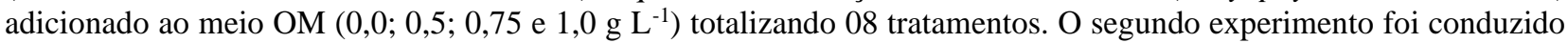
com 4 tratamentos (T1- 0,0 g L L $^{-1}$ de carvão ativado; $\mathrm{T} 2$ - 1,0 $\mathrm{g} \mathrm{L}^{-1}$ de carvão ativado, imersão e corte dos explantes em solução de ácido ascórbico na concentração de $100 \mathrm{mg} \mathrm{L}^{-1}$; T3 - 2,0 $\mathrm{g} \mathrm{L}^{-1}$ de carvão ativado, imersão e corte dos explantes em solução de ácido ascórbico na concentração de $100 \mathrm{mg} \mathrm{L}^{-1}$, e T4: 2,0 $\mathrm{g} \mathrm{L}^{-1}$ de carvão ativado). A partir dos resultados concluiu-se que, a concentração de $0,5 \mathrm{~g} \mathrm{~L}^{-1}$ de cravo-da-índia no meio OM aliada à desinfestação dos explantes com hipoclorito de sódio a $2,5 \%$ por 5 minutos apresenta resultado promissor para controle de contaminação microbiológica de segmentos nodais da oliveira cv. Koroneiki. E que o uso de carvão ativado no meio de cultura, a imersão e corte dos explantes em solução de ácido ascórbico na concentração de $100 \mathrm{mg} \mathrm{L}^{-1}$, são apropriados para redução da oxidação nos explantes.

Palavras-chave: Oleaceae; Azeitona; Antioxidantes; Micropropagação.

\begin{abstract}
The micropropagation of the olive tree is a method used to obtain several healthy seedlings in less time, compared to traditional techniques, from an explant. Thus, the objective of this work was to define a protocol of contamination and oxidation for Oliveira (Olea europaea L.) cv Koroneiki explants. For this, two experiments were performed in a completely randomized design. The first experiment was conducted in a factorial scheme (2x4), two ways of disinfesting explants with sodium hypochlorite $(\mathrm{NaClO})(1.5 \% \mathrm{NaClO} / 15 \mathrm{~min}, 2.5 \% \mathrm{NaClO} / 5 \mathrm{~min})$ and four cloves (Caryophyllus aromaticus L.) concentrations added to the culture medium $\left(0.0,0.5,0.75\right.$ and $\left.1.0 \mathrm{~g} \mathrm{~L}^{-1}\right)$ totaling 08 treatments. The second experiment was conducted with 4 treatments (T1- $0.0 \mathrm{~g} \mathrm{~L}^{-1}$ of activated charcoal; $\mathrm{T}^{-2}-1.0 \mathrm{~g} \mathrm{~L}$ ${ }^{1}$ of activated charcoal, immersion and cutting of the explants in a solution of ascorbic acid at a concentration of 100 mg L $\mathrm{L}^{-1}$; $\mathrm{T} 3$ - $2.0 \mathrm{~g} \mathrm{~L}^{-1}$ of activated charcoal, immersion and cutting of explants in ascorbic acid solution at a concentration of $100 \mathrm{mg} \mathrm{L}^{-1}$, and T4: $2.0 \mathrm{~g} \mathrm{~L}^{-1}$ of activated charcoal). From the results was possible to observe that the concentration of $0.5 \mathrm{~g} \mathrm{~L}^{-1}$ of cloves in the culture medium combined with the disinfestation of the explants with $2.5 \%$ sodium hypochlorite for 5 minutes shows promising results for control of microbiological contamination of nodal segments of olive tree cv. Koroneiki. And that the use of activated charcoal in culture medium, the immersion and cutting of the explants in a solution of ascorbic acid at a concentration of $100 \mathrm{mg} \mathrm{L}^{-1}$, presented favorable results in the reduction of oxidation in the explants.
\end{abstract}


Keywords: Oleaceae; Olive; Antioxidants; Micropropagation.

\section{Resumen}

La micropropagación del olivo es un método utilizado para obtener varias plántulas sanas en menos tiempo, en comparación con las técnicas tradicionales, a partir de un explante. En vista de esto, el objetivo de este trabajo fue definir un protocolo para el control de la contaminación y oxidación de explantes de olivo (Olea europaea L.) cv Koroneiki. Por eso, se realizaron dos experimentos de diseño aleatorio. El primer experimento se realizó en un esquema factorial $2 \mathrm{X} 4$, con dos formas de desinfestación dos explantes con hipoclorito de sodio $(\mathrm{NaClO})(1.5 \%$ $\mathrm{NaClO} / 15 \mathrm{~min}, 2.5 \% \mathrm{NaClO} / 5 \mathrm{~min}$ ) y cuatro concentraciones de clavo de olor (Caryophyllus aromaticus L.) agregado a la mitad de la $\mathrm{MO}\left(0,0 ; 0,5 ; 0,75\right.$ y $\left.1,0 \mathrm{~g} \mathrm{~L}^{-1}\right)$, totalizando 08 tratamientos. El segundo experimento se realizó con 4 tratamientos (T1- $0.0 \mathrm{~g} \mathrm{~L}^{-1}$ de carbón activado; T2 - $1.0 \mathrm{~g} \mathrm{~L}^{-1}$ de carbón activado, inmersión y corte de dos explantes en una solución de ácido ascórbico a una concentración de $100 \mathrm{mg} \mathrm{L}^{-1}$; T3 - $2.0 \mathrm{~g} \mathrm{~L}^{-1}$ de carbón activado, inmersión y corte de dos explantes en solución de ácido ascórbico a una concentración de $100 \mathrm{mg} \mathrm{L}^{-1}$, y T4: $2.0 \mathrm{~g} \mathrm{~L}^{-1}$ de carbón activado). De los resultados se concluyó que la concentración de $0.5 \mathrm{~g} \mathrm{~L}^{-1}$ clavo de olor en el medio de cultivo combinada con la desinfestación de los explantes con hipoclorito de sodio al $2.5 \%$ durante 5 minutos muestra resultados prometedores para el control de la contaminación microbiológica de segmentos nodales de olivo cv. Koroneiki. Y que el uso de carbón activado en el medio de cultivo, la inmersión y corte de los explantes en una solución de ácido ascórbico a una concentración de $100 \mathrm{mg}$. $\mathrm{L}^{-1}$, presentó resultados favorables en la reducción de la oxidación en los explantes.

Palabras clave: Oleaceae; Aceituna; Antioxidantes; Micropropagación.

\section{Introdução}

A oliveira (Olea europaea L.) pertence à família Oleaceae, sendo a única espécie da família com fruto comestível denominado azeitona. Algumas décadas atrás, o cultivo de oliveira estava limitado a países localizados na bacia do Mediterrâneo, como a Espanha, Itália e Grécia. Atualmente, no entanto, o cultivo de oliveira expandiu-se consideravelmente para áreas fora da região do Mediterrâneo, incluindo Nova Zelândia, Austrália, Argentina, Chile, Uruguai e Brasil (Crizel et al., 2020; Silva et al., 2021).

Atualmente, 10 milhões de hectares de terra no mundo estão sob o cultivo da oliveira (Haq et al., 2021). E o Brasil tem cerca de 10.000 há cultivados com oliveiras dividido em áreas localizadas no Sul e Regiões Sudeste do país, principalmente nos estados de Minas Gerais, São Paulo e Rio Grande do Sul. A produção brasileira de azeitona é quase exclusivamente dedicada à extração de azeite (Crizel et al., 2020).

O Brasil é um dos maiores importadores de produtos de oliveira da América do Sul (Pio et al. 2005; Crizel et al., 2020; Silva et al., 2021). Apesar do interesse crescente pela cultura, a olivicultura no Brasil ainda é consideravelmente baixa, devido principalmente a manejos inadequados e conhecimento deficiente de modernas técnicas de formação e condução dos pomares. As cinco principais cultivares de oliveira recentemente introduzidas e cultivadas no Brasil são Arbequina, Ascolana, Barnea, Grappolo e Koroneiki. A cultivar Koroneiki produz azeite de alta qualidade, com alta estabilidade oxidativa, sabor frutado e aroma com notas herbáceas (Silva et al., 2021).

A multiplicação da oliveira geralmente é realizada por propagação vegetativa, através da estaquia e enxertia (Porfírio et al., 2016; Santos et al., 2019). A propagação por sementes não é conveniente em função da variabilidade genética, longo período juvenil e baixa germinação em campo (Dutra et al., 2004; Fabbri et al., 2004; Porfírio et al., 2016; Santos et al., 2019). Nesse contexto, o uso de técnicas da biotecnologia moderna, como a cultura de tecidos vegetais, vem sendo usadas no melhoramento genético de plantas e para produção de mudas (Porfírio et al., 2016).

Dentre as diferentes práticas em cultura de tecidos, uma das mais utilizadas é a micropropagação de plantas in vitro, atualmente grande responsável pela produção de mudas de várias espécies para fins comerciais, tendo como vantagens a produção de mudas em menor tempo, a obtenção de várias plantas a partir de um exemplar (Oliveira; Antunes \& Schuch, 2006; Santos et al., 2019), sadias, isentas de vírus e outros microrganismos causadores de doenças (Menezes et al., 2012).

A micropropagação é um método promissor para produção de mudas de oliveira, mas que apresenta alguns problemas 
que precisam ser sanados (Fazeli-Nasab, B., Rahmani, A. \& Khajeh, H., 2021). A contaminação endógena e a oxidação fenólica dos explantes são os principais problemas para o cultivo in vitro da cultura (Cançado et al., 2012; Santos et al., 2019).

A contaminação microbiana de propágulos frequentemente ocorre sob cultivo in vitro, pois o ambiente é favorável ao crescimento de microrganismos, principalmente fungos e bactérias que podem acarretar em morte dos explantes. E no cultivo in vitro de oliveira a ocorrência da contaminação endógena é muito comum, e pode ocorrer nos feixes vasculares, floema e xilema ou nos espaços intercelulares, dificultando a desinfecção (Scherwinski-Pereira, J. E., 2010). Já a oxidação de explantes, de oliveira in vitro ocorre devido a liberação de compostos fenólicos exsudados pela própria planta, sendo necessária a aplicação no meio de cultura de substâncias antioxidantes (Cançado et al., 2012).

Várias substâncias com ação desinfetante têm sido empregadas no cultivo in vitro para assepsia de explantes, a exemplo do hipoclorito de sódio que é comumente utilizado (Santos et al., 2019). Alguns controles microbianos alternativos já estão sendo estudados, como os óleos essenciais de cravo-da-índia (Caryophyllus aromaticus L. - sinônimos taxonômicos: Eugenia cariophyllata Thunb., Syzygium aromaticum (L.), Myrtus caryophyllus Spreng., e Jambosa caryophyllus Nied) que apresentam propriedades funcionais antimicrobianas e podem ser utilizados no controle microbiológico in vitro (Jesus, G., \& Toreli, J. D., 2019). Frequentemente, adiciona-se aos meios de cultivo in vitro substâncias antioxidantes como o ácido ascórbico e carvão ativado (Oliveira, L. S., et al., 2013; Welz, V. F. F. et al., 2020).

Visando solucionar o problema de contaminação e oxidação no cultivo in vitro da oliveira o presente trabalho teve como objetivo obter um protocolo de controle de contaminação e oxidação de explantes de Olea europaea L. cultivar Koroneiki para o estabelecimento da cultura in vitro.

\section{Metodologia}

A pesquisa foi dividida em dois experimentos conduzidos no Laboratório de Micropropagação instalado no núcleo de Química, do Instituto Federal do Sudeste de Minas Gerais - Campus Barbacena. Os ramos de Olea europaea L. foram cedidos pelo Sítio Ipê situado no Município de Barbacena, Zona Rural de Correia de Almeida.

Foram utilizados segmentos nodais sem folhas e de aproximadamente $1,0 \mathrm{~cm}$ de comprimento e diâmetro médio de $0,12 \mathrm{~cm}$ como explantes excisados de brotações novas de ramos de Oliveira (Olea europaea L.) com 20 a $30 \mathrm{~cm}$ de comprimento. E, de cada ramo foi usado o segundo segmento nodal contado a partir do ápice. A planta matriz, cultivar Koroneiki, utilizada para retirada dos explante estava com 8 anos de idade e mantida em campo. Solução de hipoclorito de sódio $(\mathrm{NaClO})$ a $1 \%$ foi utilizada para assepsia da tesoura de poda imediatamente após cada excisão. Os segmentos nodais foram lavados em água corrente por 20 minutos e posteriormente levados para a desinfestação (etapas de lavagem, desinfestação e desinfecção - descritas com detalhes mais adiante) em capela.

Foi utilizado meio OM - Olive medium (Rugini, E., 1984) suplementado com sacarose a $30 \mathrm{~g} \mathrm{~L}^{-1}$, sem adição de reguladores de crescimento para o experimento 1 (controle de contaminação), $2 \mathrm{mg} \mathrm{L}^{-1}$ de zeatina e $2 \mathrm{mg} \mathrm{L}^{-1}$ de benzilaminopurina (BAP) para o experimento 2 (controle de oxidação). Solidificado com Agar 7,0 g L-1 , com pH ajustado para 5,8. O meio foi colocado em tubos de ensaio na proporção de $20 \mathrm{~mL}$ por tubo, onde estes foram vedados com tampa plástica e autoclavados (esterilizados) a $121^{\circ} \mathrm{C}$ sob pressão de $1 \mathrm{~atm}$, durante 30 minutos.

\section{Experimento 1 - Controle de contaminação in vitro}

$\mathrm{O}$ experimento foi conduzido em delineamento inteiramente casualizado, em esquema fatorial $2 \mathrm{X} 4$, sendo duas formas de desinfestação dos explantes com solução hipoclorito de sódio $(\mathrm{NaClO})$ - duas concentrações em percentagem de cloro ativo - $(1,5 \% \mathrm{NaClO} / 15 \mathrm{~min}$ e $2,5 \% \mathrm{NaClO} / 5 \mathrm{~min})$ e quatro concentrações de cravo-da-índia (Caryophyllus aromaticus L.) adicionado ao meio de cultura $\left(0,0 ; 0,5 ; 0,75\right.$ e $\left.1,0 \mathrm{~g} \mathrm{~L}^{-1}\right)$ totalizando 08 tratamentos, com 07 repetições cada. A unidade 
experimental foi constituída de dois tubos de ensaio com um segmento nodal cada. Utilizou-se o meio de cultura OM acrescido de $2 \mathrm{mg} \mathrm{L}^{-1}$ de ácido ascórbico e $2 \mathrm{~g} \mathrm{~L}^{-1}$ de carvão ativado.

Em câmara de fluxo laminar os explantes foram submetidos à desinfestação com solução de álcool 70\% sob agitação constante por $1 \mathrm{~min}$, em seguida transferidos para solução de hipoclorito de sódio (NaClO) contendo duas gotas de Tween 20, sob agitação constante. Posteriormente, os explantes foram submetidos à quatro enxagues em água destilada e autoclavada. Após a desinfestação dos segmentos nodais em câmara de fluxo laminar, estes foram inoculados em tubos e posteriormente lacrados com filme plástico PVC (policloreto de vinila).

Os tubos permaneceram na ausência de luz por 7 dias e após este período foram transferidos para sala de crescimento padrão com intensidade luminosa de $27 \mu \mathrm{mol} \mathrm{m}^{-2} \mathrm{~s}^{-1}$, temperatura $25 \pm 2^{\circ} \mathrm{C}$ e fotoperíodo de 16 horas de luz. Após 15 dias da inoculação (DAI), os explantes foram avaliados quanto à contaminação e oxidação, pois sabe-se que utilização de agentes desinfetantes como o hipoclorito de sódio tem potencial de causar o aumento do estresse oxidativo.

\section{Experimento 2 - Controle de oxidação in vitro}

De posse dos resultados do experimento 1, identificou-se a melhor forma de desinfestação para o controle da contaminação e, após verificação da oxidação dos explantes submetidos à solução de hipoclorito, iniciou-se o experimento 2; onde utilizou-se a forma mais adequada de desinfestação encontrada no experimento 1 ( $2,5 \% \mathrm{NaClO} / 5 \mathrm{~min}$ ) e dois produtos antioxidantes para o controle de oxidação visando o estabelecimento in vitro de plantas de oliveira. Utilizou-se o meio de cultura OM com adição de $2 \mathrm{mg} \mathrm{L}^{-1}$ de zeatina e $2 \mathrm{mg} \mathrm{L}^{-1}$ de BAP.

$\mathrm{Na}$ capela de fluxo laminar os explantes foram submetidos à desinfestação com solução de álcool $70 \%$ sob agitação constante por $1 \mathrm{~min}$, em seguida transferidos para solução de hipoclorito de sódio ( $\mathrm{NaClO})$ na concentração de 2,5\% de cloro ativo e adicionado 2 gotas de Tween 20 sob agitação constante por 5 min e quatro enxagues em água destilada e autoclavada. Após a desinfestação dos segmentos nodais em capela, estes foram inoculados nos tubos e posteriormente lacrados com filme plástico PVC.

Os tubos de ensaio permaneceram na ausência de luz por 7 dias, e após este período transferidos para sala de

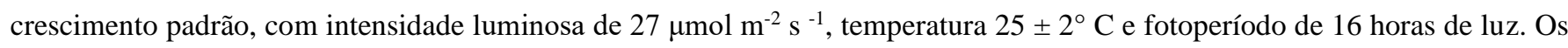
explantes foram avaliados quanto a oxidação aos 7 e 15 dias após a inoculação (DAI).

Foi utilizado o delineamento inteiramente casualizado, com 4 tratamentos e 10 repetições, totalizando 40 parcelas. A constituição de cada unidade experimental foi de um tubo de ensaio contendo um segmento nodal (explante) em cada tubo. Os tratamentos foram os seguintes: T1 (0,0 $\mathrm{g} \mathrm{L}^{-1}$ de carvão ativado acrescido no meio $\left.\mathrm{OM}\right)$; T2 (1,0 $\mathrm{g} \mathrm{L}^{-1}$ de carvão ativado acrescido no meio OM, base dos ramos imergidos em $100 \mathrm{mg} \mathrm{L}^{-1}$ de ácido ascórbico por 3 minutos e corte dos explantes em solução de ácido ascórbico $\left.100 \mathrm{mg} \mathrm{L}^{-1}\right)$; T3 (2,0 $\mathrm{g} \mathrm{L}^{-1}$ de carvão ativado acrescido no meio OM, base dos ramos imergidos em $100 \mathrm{mg} \mathrm{L}^{-1}$ de ácido ascórbico por 3 minutos e corte dos explantes em solução de ácido ascórbico $\left.100 \mathrm{mg} \mathrm{L}^{-1}\right)$; T4 (2,0 g L $\mathrm{g}^{-1}$ de carvão ativado acrescido no meio OM).

\section{Análises estatísticas}

Os dados obtidos foram submetidos à análise de variância, utilizando o software estatístico SISVAR (Ferreira, 2011) com aplicação do teste de Scott-Knott a 5\% de significância.

O teste não paramétrico de Kruskal Wallis a 5\% de probabilidade foi aplicado visando uma melhor interpretação dos resultados com a finalidade de comparar os tratamentos como um todo e determinar a melhor combinação dos fatores analisados (Pimentel Gomes, F.,1985; Cargnelutti Filho et al., 2001). Sendo assim, para as variáveis não paramétricas de contaminação (fúngica e bacteriana) foram aplicadas as notas 0 e 1, as quais se referem a: 0 - sem ocorrência de contaminação; 
1 - contaminação fúngica e, ou bacteriana. Já para a variável oxidação, as notas foram atribuídas conforme sintoma visual observado nos explantes ( 0 - sem oxidação; 1 - explante oxidado).

\section{Resultados e Discussão}

\section{Experimento 1 - Controle de contaminação in vitro}

De acordo com as análises de variância a contaminação e oxidação dos explantes avaliados aos 15 dias após a inoculação (DAI) não foram influenciadas pela interação dupla entre os fatores estudados (formas de desinfestação de explantes e concentrações de cravo-da-índia). E que não houve diferenças significativas para variáveis contaminação e oxidação entre as concentrações de cravo-da-índia. Já a variável contaminação de explantes submetidos a diferentes formas de desinfestação com hipoclorito de sódio $(\mathrm{NaClO})$ apresentou diferenças significativas, sendo que, a desinfestação por meio da concentração de 2,5\% de $\mathrm{NaClO}$ e tempo de permanência na solução por 5 minutos apresentou cerca de $56 \%$ menos contaminações comparada à outra forma de desinfestação (Figura 1). A baixa porcentagem de contaminação alcançada reflete a eficiência do método de desinfestação adotado neste ensaio. Contudo, diferentemente dos resultados obtidos neste estudo Santos et al., 2019 observaram que uma concentração menor de $\mathrm{NaClO}(1,0 \%)$ utilizada no processo de desinfestação adicionada ao meio de cultura apresentou resultado promissor para o estabelecimento in vitro da cultivar Koroneiki.

Figura 1. Contaminação in vitro de explantes de Olea europaea L. cv Koroneiki submetidos a diferentes formas de desinfestação com hipoclorito de sódio ( $\mathrm{NaClO}$ ) avaliados 15 dias após inoculação (DAI). Médias seguidas de mesma letra, não diferem entre si (Scott-Knott, 5\%).

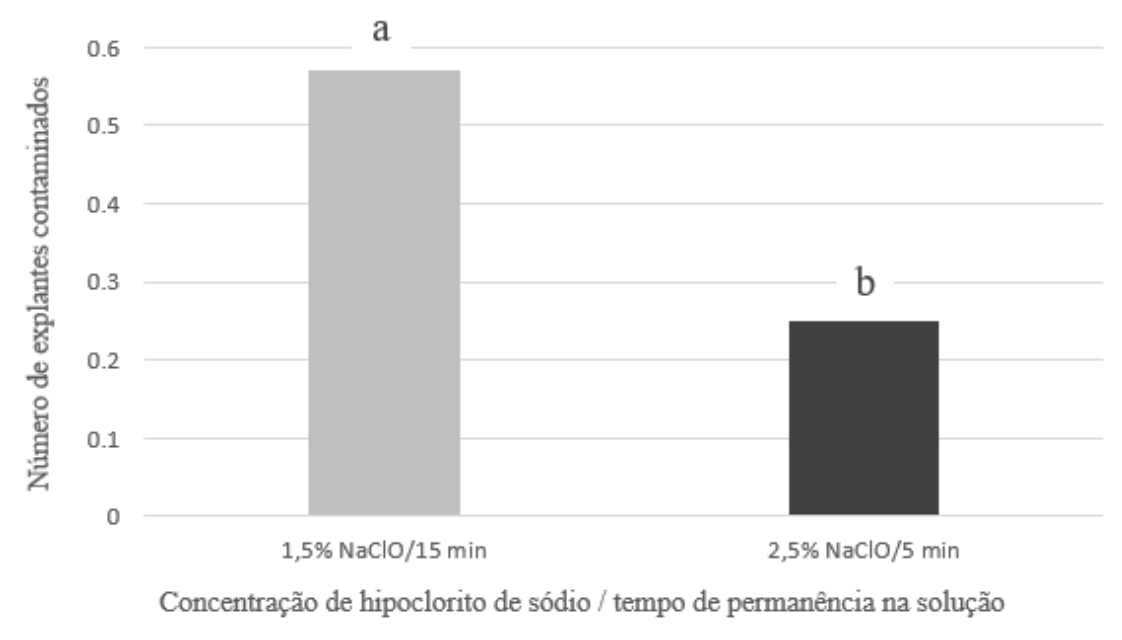

Fonte: Autoras.

De acordo com o teste de Kruskal Wallis ( $\mathrm{p}<0,05)$, o comportamento dos tratamentos para as variáveis contaminação e oxidação foi semelhante (Figura 2). Porém, para a variável contaminação (Figura 2A), o T3 (1,5\% NaClO/15min + 0,75 g.L-1 cravo-da-índia) apresentou maior contaminação em relação aos demais tratamentos, com somatório total igual a 05. Enquanto que, o tratamento com menor incidência de contaminação foi o T6 (2,5\% NaClO/15min + 0,50 gL $\mathrm{gL}^{-1}$ de cravo-da-índia), com somatório igual a 1 , ou seja, $80 \%$ menos contaminação indicando ser esse o melhor tratamento, dentre os estudados, para controle de contaminação microbiológica de segmentos nodais da oliveira cv. Koroneiki. 
Figura 2. Teste de Kruskal Wallis para os dados de somatório de contaminação microbiológica (A) e somatório de oxidação (B) de segmentos nodais de Olea europaea L. cv Koroneiki in vitro avaliados 15 dias após inoculação (DAI).

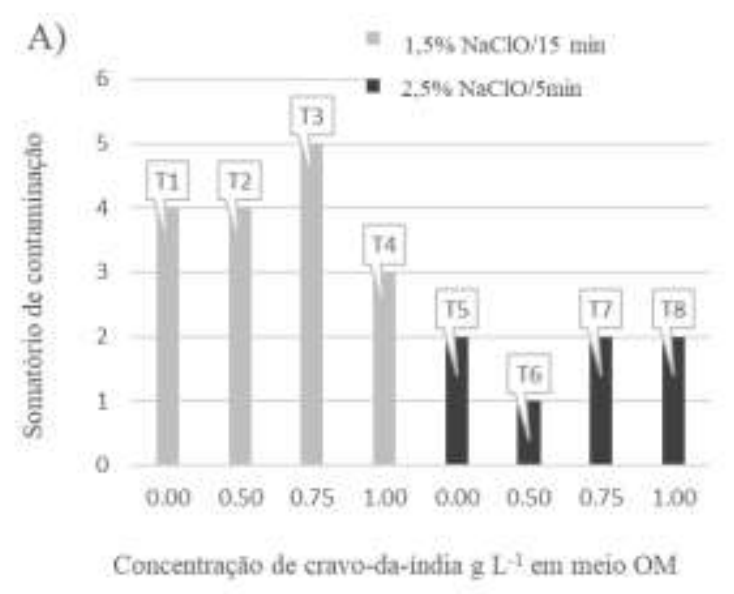

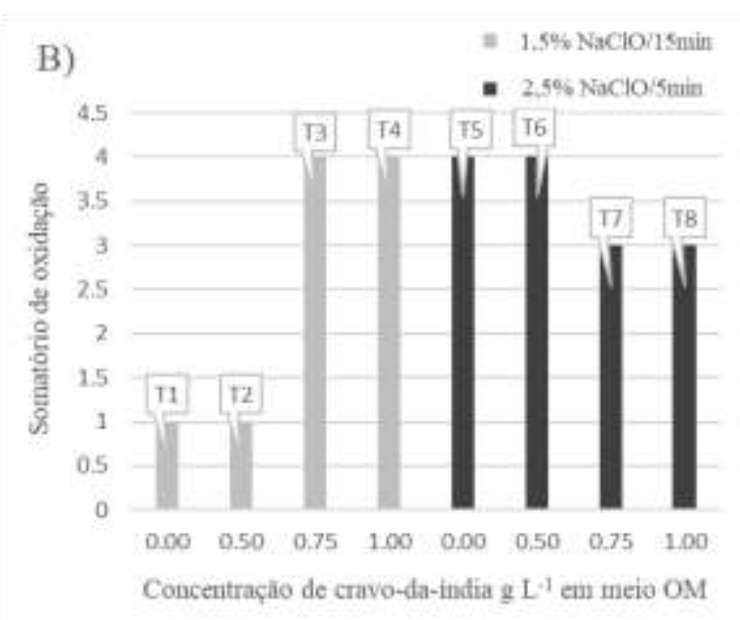

Fonte: Autoras.

Vale ressaltar que, as contaminações dos explantes, onde há presença de cravo-da-índia no meio OM (T2, T3, T4, T6, T7 e T8) ocorreram por fungos; nos tratamentos T1 e T5 as contaminações foram causadas por bactérias, ambos sob ausência de cravo-da-índia no meio. Logo, a presença de cravo-da-índia no meio de cultura inibe a contaminação bacteriana. Esse efeito pode ser explicado pelo fato de o cravo-da-índia apresentar o eugenol, uma substância com ação bactericida (Kume et al., 2021). Guimarães et al., 2017 verificaram a atividade inibitória in vitro de óleo essencial de cravo-da-índia em cepas de bactérias de Staphylococcus aureus e Escherichia coli. E, os autores Amorim et al., (2011) averiguaram que o óleo de cravoda-índia foi capaz de inibir o crescimento in vitro de bactérias Ralstonia solanacearum.

A origem dos explantes utilizados neste estudo também pode ter influenciado negativamente no controle eficiente da contaminação endógena in vitro, pois a planta matriz já permanecia em campo por 8 anos. Este acontecimento foi constatado por Gonçalves et al., (2013), que utilizou para estabelecimento in vitro de oliveira explantes retirados de plantas mantidas em campo e averiguou que a dificuldade do controle da contaminação endógena de explantes de oliveira pode ter como causas o fato dos explantes terem sido retirados dessas plantas, sem controle preventivo adequado. Porfírio et al., 2016 também relatam a importância dos aspectos fitossanitários da planta-mãe para viabilidade e vigor de seus explantes.

Em relação a variável oxidação dos explantes (Figura 2B), os tratamentos T3, T4, T5 e T6 apresentaram maiores níveis de oxidação, totalizando somatório de 04 explantes oxidados em cada tratamento. Os tratamentos que apresentaram menor somatório de oxidação foram os T1 e T2 com total de 01 cada, ou seja, uma diferença de cerca de $75 \%$ entre os maiores e menores valores encontrados.

Pode-se notar pelas Figuras 1 e 2A que os segmentos nodais de oliveira da cv. Koroneiki submetidos à desinfestação por solução de $2,5 \% \mathrm{NaClO}$ por 5 minutos mostraram menores incidências de contaminações, contudo, os explantes sob essa forma de desinfestação apresentaram maiores ocorrências de oxidações (Figura 2B). A oxidação está ligada à concentração de hipoclorito de sódio utilizada no processo de assepsia (Pereira et al., 2020). A utilização de agentes desinfetantes como o hipoclorito de sódio tem potencial de causar o aumento do estresse oxidativo (Trevelin, 2014), processo derivado de um desequilíbrio entre a produção de compostos oxidantes e a atuação dos sistemas de defesa antioxidante (Halliwell; Whiteman, 2004). 
Diante do contexto notamos que, a forma de desinfestação mais promissora foi a que se fez uso de $2,5 \%$ de hipoclorito de sódio com permanência dos explantes por $5 \mathrm{~min}$, porém há uma maior incidência de oxidação nessas condições. A oxidação ocorre em função da liberação de compostos fenólicos in vitro, precursores da síntese de lignina, pelo tecido injuriado e necessita de aplicação de produtos antioxidantes (Andrade et al., 2000). Assim, no experimento 2, a seguir, fez-se uso da melhor forma de desinfestação encontrada neste estudo $(2,5 \% \mathrm{NaClO} / 5 \mathrm{~min})$ aliada ao uso de substâncias inibidoras de oxidação visando encontrar métodos satisfatórios para o cultivo da oliveira in vitro.

\section{Experimento 2 - Controle de oxidação in vitro}

De acordo com as análises de variância, houve diferença significativa entre os tratamentos avaliados aos 7 dias após inoculação (DAI) e não apresentaram diferenças significativas para a segunda avaliação aos 15 DAI (Figura 3). No tratamento T1 não se utilizou produtos antioxidantes, consequentemente a oxidação foi maior, já nos tratamentos submetidos a substâncias inibitórias de oxidação (T2, T3 e T4) notou-se redução significativa da mesma (Figura 3).

Figura 3. Oxidação in vitro de explantes de Olea europaea L. cv Koroneiki submetidos a diferentes tratamentos avaliados aos 7 e 15 dias após inoculação (DAI). Tratamentos: T1 (0,0 $\mathrm{g} \mathrm{L}^{-1}$ de carvão ativado); T2 (1,0 $\mathrm{g} \mathrm{L}^{-1}$ de carvão ativado, imersão e corte dos explantes em ácido ascórbico); T3 (2,0 $\mathrm{g} \mathrm{L}^{-1}$ de carvão ativado, imersão e corte dos explantes em ácido ascórbico) e T4 (2,0 $\mathrm{g} \mathrm{L}^{-1}$ de carvão ativado). Médias seguidas de mesma letra, não diferem entre si (Scott-Knott, $5 \%$ ).
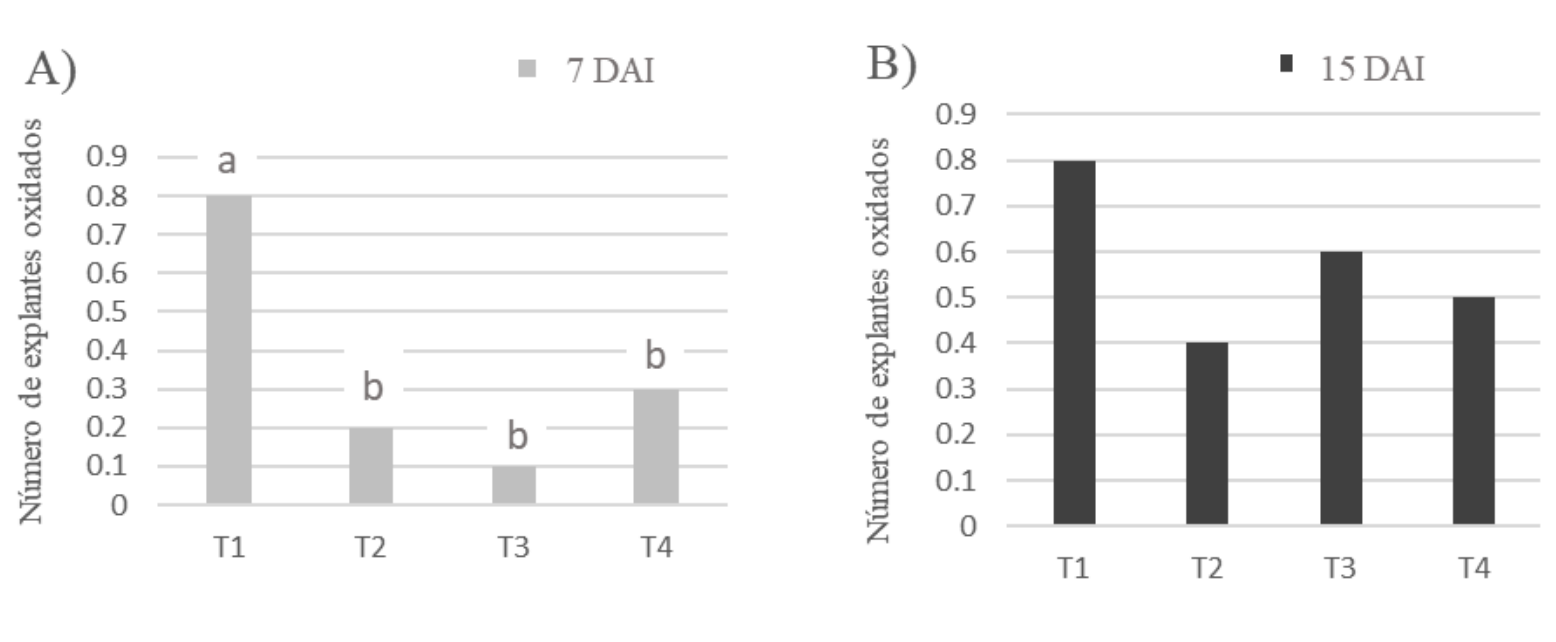

Fonte: Autoras.

Não foi observada diferença entre os tratamentos em relação à adição de ácido ascórbico (T2 e T3) (Figuras 3A e 3B), porém o ácido ascórbico tendeu a reduzir oxidação, aos $7 \mathrm{DAI}$, conforme pode ser observado pelo tratamento T3 $\left(2 \mathrm{~g} \mathrm{~L}^{-1} \mathrm{de}\right.$ carvão ativado + ácido ascórbico) em comparação com o T4 (2 g L-1 de carvão ativado) (Figura 3A). Segundo Goulart et al. (2010), o ácido ascórbico reage com os metais presentes no meio de cultura, impedindo que estes fiquem disponíveis para se oxidarem. Melo et al., (2001), verificou no cultivo in vitro de Guarirobeira (Syagrus oleracea) que o ácido ascórbico foi o antioxidante mais eficiente no controle da oxidação, seguido pelo carvão ativado.

Conforme o teste de Kruskal Wallis ( $\mathrm{p}<0,05)$, em avaliação realizada aos 7 DAI o desempenho dos tratamentos para a variável oxidação diferiu entre os tratamentos T1, sem adição de produtos antioxidantes, e T3 em que se utilizou maior concentração de carvão ativado $\left(2 \mathrm{~g} \mathrm{~L}^{-1}\right)$ com adição de ácido ascórbico, variando o somatório de oxidação de explantes de 08 a 01, sendo essa variação cerca de 87\% (Figura 4A). Foi possível observar que os tratamentos T2 e T3 apresentaram baixo 
somatório de oxidação, o que demonstraria a forte influência dos produtos antioxidantes (carvão ativado + ácido ascórbico) no papel desta variável. Em concordância ao encontrado neste trabalho, Haq et al., 2021 relatam que o tratamento com ácido ascórbico e carvão ativado são metódos eficazes no controle de oxidação ocasionda por compostos fenólicos que podem causar escurecimento do tecido vegetal da oliveira.

Figura 4. Teste de Kruskal Wallis para os dados de somatório de oxidação de segmentos nodais de Olea europaea L. cv Koroneiki in vitro submetidos a diferentes tratamentos e avaliados aos 7 e 15 dias após inoculação (DAI), Figuras 4(A) e 4(B) respectivamente, após inoculação. Tratamentos: T1 (0,0 $\mathrm{g} \mathrm{L}^{-1}$ de carvão ativado); T2 (1,0 $\mathrm{g} \mathrm{L}^{-1}$ de carvão ativado, imersão e corte dos explantes em ácido ascórbico); T3 (2,0 $\mathrm{g} \mathrm{L}^{-1}$ de carvão ativado, imersão e corte dos explantes em ácido ascórbico) e T4 (2,0 $\mathrm{g} \mathrm{L}^{-1}$ de carvão ativado). Somatórios seguidos por símbolos $\left(^{*}\right)$ apresentam diferenças estatisticamente significativas entre as medianas $(\mathrm{p} \leq 0,5)$.

(A)

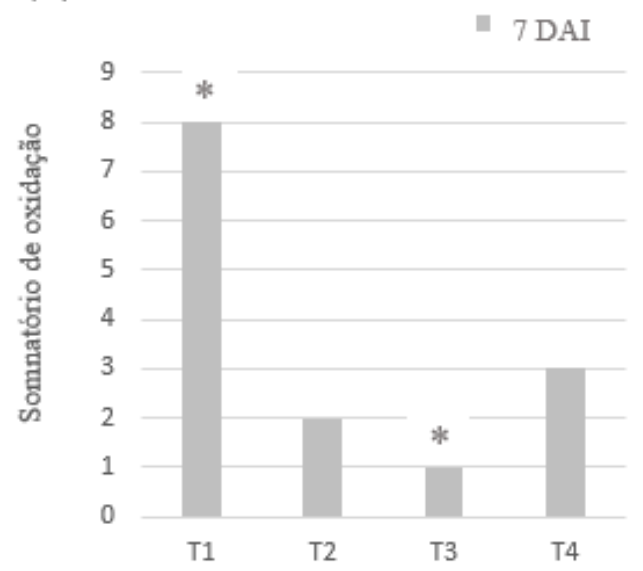

(B)

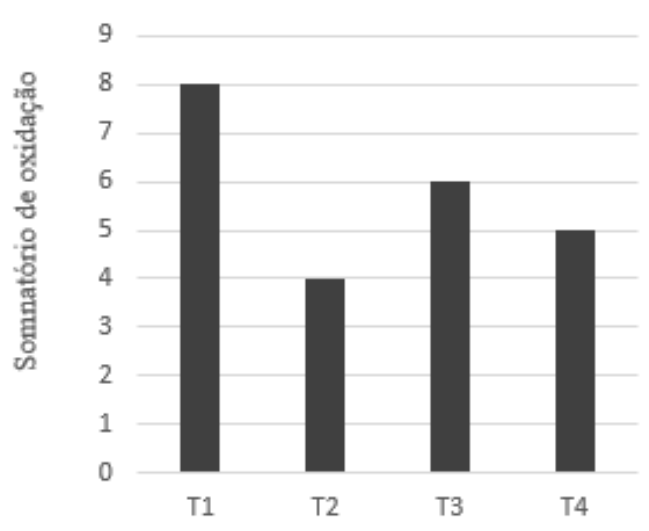

Fonte: Autoras.

O desempenho dos tratamentos para a variável oxidação aos 15 DAI foi parecido, porém o T1 (sem adição de produtos antioxidantes) apresentou maior oxidação em relação aos demais tratamentos, com somatório total igual a 08. Em contrapartida, o tratamento com menor ocorrência de oxidação foi o T2 (1,0 g L ${ }^{-1}$ de carvão ativado + ácido ascórbico), com somatório total igual a 04, sendo essa variação de 50\% (Figura 4B).

Pode-se observar, também, a eficiência do carvão ativado no tratamento T4 (2 $\mathrm{g} \mathrm{L}^{-1}$ de carvão ativado), tanto aos 7 DAI quanto aos 15 DAI (Figura 04), comparado ao T1 (sem carvão e sem ácido ascórbico), situação na qual tendeu a reduzir a oxidação pela adição de carvão ativado ao meio OM. O carvão ativado apresenta cargas residuais, as quais são capazes de adsorver substâncias fenólicas ou seus produtos da oxidação liberados pelos explantes, evitando com isso o desencadeamento do processo oxidativo in vitro (Thomas, T. D. 2008; Goulart et al., 2010).

Nas duas avaliações (7 DAI e 15 DAI) (Figura 04), o tratamento (T1) obteve a maior oxidação, o tratamento T3 inicialmente apresentou os melhores resultados, aos 7 DAI - situação em que estavam sob ausência de luz, mas após a transferência para a presença de luz branca (15 DAI) a oxidação aumentou.

Melo et al., (2001) verificaram que a atividade das enzimas no que diz respeito a oxidação de fenóis é aumentada pela luz. Segundo Davies (1972), a biossíntese e oxidação de fenóis é aumentada pela luz, o que explica o fato dos explantes de oliveira terem aumentado a oxidação quando transferidos para o ambiente claro. Contudo, Donini et al., (2008) em estudos in vitro com diferentes cultivares de oliveira observaram que a cultivar Koroneiki, objeto deste estudo, apresentou adequado 
vigor relativo à oxidação quando cultivada sob luz branca comparada às demais cultivares avaliadas, atribuindo-se este fato às menores concentrações de compostos fenólicos totais e aos diferentes tipos de fenóis existentes nos tecidos desta cultivar. Santos et al., 2019 mencionam que estes compostos, ao entrarem em contato com o oxigênio, desencadeiam reações de oxidação resultando em produtos tóxicos que ocasionam o escurecimento e a necrose do tecido vegetal.

Diante do exposto e através das respostas dos experimentos 1 e 2 pode-se notar que os resultados obtidos pelo teste de Scott Knott $(\mathrm{p}<0,05)$ foram confirmados pelo teste não paramétrico de Kruskal Wallis $(\mathrm{p}<0,05)$ no qual observou-se respostas positivas em relação ao uso da forma de desinfestação de 2,5\% NaClO por 5 minutos de permanência na solução e que uso de carvão ativado e ácido ascórbico diminuem a oxidação de explantes de oliveira cv Koroneiki.

\section{Considerações Finais}

A oliveira apresenta dificuldades para o cultivo in vitro em virtude, principalmente, da oxidação e contaminação dos explantes. Entretanto, a desinfestação com 2,5\% de hipoclorito de sódio por 5 minutos apresenta resultado promissor para controle de contaminação microbiológica de segmentos nodais da oliveira cv. Koroneiki. Este resultado destaca-se pelo fato de que ainda não existe publicação científica de um método de desinfestação eficaz para esta cultivar.

A concentração de $0,5 \mathrm{~g} \mathrm{~L}^{-1}$ de cravo-da-índia no meio de cultura aliada à desinfestação com hipoclorito de sódio a 2,5\% por 5 minutos apresenta os melhores resultados para controle de contaminação microbiológica de segmentos nodais.

O uso de carvão ativado no meio de cultura, a imersão e corte dos explantes em solução de ácido ascórbico na concentração de $100 \mathrm{mg} \mathrm{L}^{-1}$, demonstram ser apropriados para redução da oxidação nos explantes de oliveira.

Outros testes com diferentes concentrações de hipoclorito de sódio, cravo-da-índia, carvão ativado e combinações com ácido ascórbico são necessários para se efetivar um protocolo específico de controle de contaminação e oxidação de explantes de Olea europaea L. cv Koroneiki e posterior estabelecimento da cultura in vitro.

\section{Referências}

Amorim, E. P. D. R., Andrade, F. W. R. D., Moraes, E. M. D. S., Silva, J. C. D., Lima, R. D. S., \& Lemos, E. E. P. D. (2011). Atividade antibacteriana de óleos essenciais e extratos vegetais sobre o desenvolvimento de Ralstonia Solanacearum em mudas de bananeira. Revista Brasileira de Fruticultura, 33(SPE1), 392-398. http://dx.doi.org/10.1590/S0100-29452011000500050

Andrade, M. D., Luz, J. M. Q., \& Lacerda, A. S. (2000). Micropropagação da aroeira (Myracroduon urundeuva Fr. All). Ciência e Agrotecnologia, Lavras, 24(1), 174-180.

Cançado, G. M. de A., Braga, F. T., Souza de R. A. V., Nunes, C. F., Ribeiro, A. P., \& Soares, B. D. F. (2012). Cultivo in vitro da oliveira e suas aplicações: In: Oliveira, A. F. Oliveira no Brasil: tecnologias de produção. Epamig. cap.10, p. 275-310.

Cargnelutti Filho, A. (2001). Testes não paramétricos para pesquisas agrícolas. Santa Maria: UFSM/CCR/Departamento de Fitotecnia.

Crizel, R. L., Hoffmann, J. F., Zandoná, G. P., Lobo, P. M. S., Jorge, R. O., \& Chaves, F. C. (2020). Characterization of extra virgin olive oil from Southern Brazil. European Journal of Lipid Science and Technology, 122(4), 1900347. https://doi.org/10.1002/ejlt.201900347

Davies, M. E. (1972). Polyphenol synthesis in cell suspension cultures of Paul's Scarlet rose. Planta, 104(1), 50-65. https://doi.org/10.1007/BF00387683

Donini, L. P., Schuch, M. W., de Farias Ribeiro, M., de Souza, J. A., \& Soares, G. C. (2008). Avaliação da resposta de três cultivares de oliveira ao cultivo in vitro sob diferentes comprimentos de onda luminosa e efeitos da combinação de zeatina e ácido giberélico. Scientia agraria, 9(2), 229-233. http://dx.doi.org/10.5380/rsa.v9i2.11008

Dutra, L. F., Oliveira, A. F. D., Fráguas, C. B., \& Pasqual, M. (2004). Multiplicação in vitro de oliveira (Olea europaea L.). Ciência e Agrotecnologia, 28(1), 220-223. https://doi.org/10.1590/S1413-70542004000100030

Fabbri, A. G., Bartolini, G., Lambardi, M., \& Kailis, S. (2004). Olive propagation manual. Landlinks Press.

Fazeli-Nasab, B., Rahmani, A., \& Khajeh, H. (2021). Effects of culture medium and plant hormones in organogenesis in olive (CV. Kroneiki). Journal of Plant Bioinformatics and Biotechnology, 1(1), 1-13. 10.22034/jpbb.2021.122590

Ferreira, D. F. (2011). Sisvar: a computer statistical analysis system. Ciência e agrotecnologia, 35(6), 1039-1042. https://doi.org/10.1590/S141370542011000600001 
Gonçalves, T. S., Barbosa, W. M., Nannetti, D. C., dos Santos, L. G. M., Caproni, D. T. R., \& Melo, F. (2013, October). Oxidação in vitro de Olea europaea L. In $5^{a}$ Jornada Científica e Tecnológica e $2^{o}$ Simpósio da Pós-Graduação. https://jornada. ifsuldeminas.edu.br/index.php/jcinc/jcinc/paper/viewFile/266/119

Goulart, P. B., Xavier, A., \& Dias, J. M. M. (2010). Efeito de antioxidantes no enraizamento de mini estacas de clones de Eucalyptus grandis x E. urophylla. Revista Árvore, 34(6), 961-972. https://doi.org/10.1590/S0100-67622010000600001

Guimarães, C. C., Ferreira, T. C., de Oliveira, R. C. F., Simioni, P. U., \& Ugrinovich, L. A. (2017). Atividade antimicrobiana in vitro do extrato aquoso e do óleo essencial do alecrim (Rosmarinus officinalis L.) e do cravo-da-índia (Caryophyllus aromaticus L.) frente a cepas de Staphylococcus aureus e Escherichia coli. Revista Brasileira de Biociências, 15(2). http://www.ufrgs.br/seerbio/ojs/index.php/rbb/article/view/3877

Halliwell, B., \& Whiteman, M. (2004). Measuring reactive species and oxidative damage in vivo and in cell culture: how should you do it and what do the results mean? British journal of pharmacology, 142(2), 231-255. https://doi.org/10.1038/sj.bjp.0705776

Haq, I. U., Umar, H., Akhtar, N., Iqbal, M. A., \& Ijaz, M. (2021). Techniques for Micropropagation of Olive (Olea europaea L.): A Systematic Review. Pakistan Journal of Agricultural Research, 34(1), 184. http://dx.doi.org/10.17582/journal.pjar/2021/34.1.184.192

Jesus, G., \& Toreli, J. D. (2019). Efeitos Antimicrobianos dos Extratos de Syzygium aromaticum (L.) Merr. \& Perry Aplicados à Saúde, Indústria e Agricultura. Atas de Saúde Ambiental-ASA (ISSN 2357-7614), 7(1), 113.

Kume, J. E. P., Junior, R. A., Di-Tanno, M. F. P., \& Kozusny-Andreani, D. I. (2021). Uso de óleos essenciais in natura e ozonizados no controle in vitro de Trichophyton mentagrophytes. Research, Society and Development, 10(1), e4710111233-e4710111233. http://dx.doi.org/10.33448/rsd-v10i1.11233

Melo, B., Pinto, J. E. B. P., Luz, J. M. Q., Peixoto, J. R., \& Juliatti, F. C. (2001). Diferentes antioxidantes no controle da oxidação, germinação e desenvolvimento das plântulas na cultura in vitro de embriões da guarirobeira [Syagrus oleracea (Mart.) Becc.]. Ciência e Agrotecnologia, 25(6), $1301-1306$.

Menezes, T. P., Gomes, W. A., Pio, L. A. S., Pasqual, M., \& Ramos, J. D. (2012). Micropropagação e endorreduplicação em pitaya vermelha. Bioscience Journal, 28(6). http://www.seer.ufu.br/index.php/biosciencejournal/article/view/13986/11095

Oliveira, A. D., Antunes, L. E. C., \& Schuch, M. W. (2006). Caracterização morfológica de cultivares de oliveira em coleção e considerações sobre o seu cultivo no Brasil. Informe agropecuário, 27(231), 55-62.

Oliveira, L. S., Dias, P. C., \& Brondani, G. E. (2013). Micropropagação de espécies florestais brasileiras. Pesquisa florestal brasileira, 33(76), 439-453. 10.4336/2013.pfb.33.76.481

Pereira, W. J., Issa, C. G. C., de Pinto, A. F., Lemos, D. C. S., Barbosa, A. M., Pereira, K. C., de Paula, M. S. P., \& do Carmo Vieira, M. (2020). Estabelecimento in vitro de bananeiras em diferentes meios de cultura submetidas a agentes antioxidantes. Brazilian Journal of Development, 6(1), 4973-4984. 10.34117/bjdv6n1-359:

Pimentel Gomes, F. (1985). Curso de estatística experimental. 11 ed. rev. ampl. Piracicaba, Nobel, 1985, 56-76.

Pio, R., Bastos, D. C., Berti, A. J., Scarpare Filho, J. A., Mourão Filho, F. D. A. A., Entelmann, F. A., Alves, A. S. R., \& Bettiol Neto, J. E. (2005), Enraizamento de diferentes tipos de estacas de oliveira (Olea europaea L.) utilizando ácido indolbutírico. Ciência e Agrotecnologia, 29(3), 562-567. http://dx.doi.org/10.1590/S1413-70542005000300008.

Porfírio, S., da Silva, M. D. G., Cabrita, M. J., Azadi, P., \& Peixe, A. (2016). Reviewing current knowledge on olive (Olea europaea L.) adventitious root formation. Scientia Horticulturae, 198, 207-226. https://doi.org/10.1016/j.scienta.2015.11.034

Santos, J. D., Pinheiro, M. V. M., Fontana, D. C., Schmidt, D., \& Pretto, M. M. (2019). Estabelecimento in vitro de oliveira 'Arbequina'e 'Koroneiki'. Ciência Florestal, 29(2), 508-518. https://doi.org/10.5902/1980509831305

Scherwinski-Pereira, J. E. (2010). Contaminações microbianas na cultura de células, tecidos e órgãos de plantas. Embrapa Informação Tecnológica. http://livimagens.sct.embrapa.br/amostras/00083840

Silva, B. S., \& Schmiele, M. (2021). From olive to olive oil: a general approach. Research, Society and Development, 10(3). https://doi.org/10.33448/rsdv10i3.13408

Rugini, E. (1984). In vitro propagation of some olive (Olea europaea sativa L.) cultivars with different root-ability, and medium development using analytical data from developing shoots and embryos. Scientia Horticulturae, 24(2), 123-134. https://doi.org/10.1016/0304-4238(84)90143-2

Thomas, T. D. (2008). The role of activated charcoal in plant tissue culture. Biotechnology advances, 26(6), 618-631. https://doi.org/10.1016/j.biotechadv.2008.08.003

Trevelin, V. (2014). Micropropagação de Plantas Ornamentais - Gypsophila paniculata e Dracaena sanderiana. 2014. Dissertação (Mestrado em Fisiologia Vegetal)__Programa de pós-graduação em Fisiologia Vegetal, Instituto de Biologia, Universidade Federal de Pelotas, Pelotas.

Welz, V. F. F., Trettel, J. R., Nascimento, A. B., \& Magalhães, H. (2020). Growth, enzymatic activity, and antioxidant activity of sweet basil grown in vitro. Revista Caatinga, 33(3), 660-670. http://dx.doi.org/10.1590/1983-21252020v33n309rc 